\title{
A double-blind randomized study of cisapride in the treatment of nonulcer dyspepsia
}

\author{
MC CHAMPION MB FRCPC FRCP(UK), KL MACCANNELL BSc PhD FACP FRCPC, ABR THOMSON MD PhD FRCPC FACG, \\ R TANTON MD FRCPC, S EBERHARD ABIM FACP FRCCP, SN SULLIVAN MD FRCPC, A ARCHAMBAULT MD FRCPC, \\ FOR THE CANADIAN CISAPRIDE NUD STUDY GROUP
}

\begin{abstract}
MC Champion, KL MACCANnell, ABR ThOMSON, ET AL, FOR THE CANADIAN CISAPRIDE NUD STUDY GROUP. A double-blind randomized study of cisapride in the treatment of nonulcer dyspepsia. Can J Gastroenterol 1997;11(2):127-134. Cisapride is a substituted benzamide with gastrointestinal prokinetic effects presumed to be due to the enhancement of the physiological release of acetylcholine at the myenteric plexus. In a multicentre study, 189 patients with nonulcer dyspepsia (NUD) received single-blind placebo treatment for two weeks. A total of 123 patients with no or minimal response to placebo and epigastric pain of at least moderate severity and frequency were randomly assigned to one of three parallel double-blind treatments for six weeks: cisapride $10 \mathrm{mg}$ tid, cisapride $20 \mathrm{mg}$ tid or placebo. The severity and frequency of individual symptoms (epigastric pain, heartburn, nausea, vomiting, anorexia, postprandial discomfort, regurgitation, lower abdominal pain, bloating and constipation) were assessed on a four- and five-point categorical scale, respectively, by the investigator at three on-treatment visits and by patients in a daily diary. Analysis of investigator and patient assessments for differences in symptom severity $\mathrm{X}$ frequency composite scores among the three treatment groups showed no statistically significant differences for individual symptoms or symptom clusters. As assessed by the investigator, and compared with baseline, cisapride $20 \mathrm{mg}$ tid significantly $(\mathrm{P}<0.05)$ improved epigastric pain, bloating and early satiety as well as improved the total
\end{abstract}

symptom cluster. Investigator evaluation of the five most severe and frequent symptoms for each patient showed statistically significant improvement in each treatment group. For patient diary assessments, statistically significant within-treatment improvement of the total symptom cluster, the five most severe symptoms cluster, bloating and early satiety was observed for both cisapride $20 \mathrm{mg}$ and placebo, whereas epigastric pain significantly $(\mathrm{P}<0.05)$ improved in all three treatment groups. Investigator evaluation of global response (good + excellent) rate at the end of the six-week treatment period was $38 \%$ for cisapride $20 \mathrm{mg}, 47 \%$ for cisapride $10 \mathrm{mg}$ and $33 \%$ for placebo. No statistically significant difference in this parameter among treatments was noted. Cisapride was well tolerated at both doses with a side effect profile comparable with that of placebo. It is concluded that, in this double-blind multicentre study with a single-blind two-week placebo run-in phase, cisapride $10 \mathrm{mg}$ tid and $20 \mathrm{mg}$ tid were not effective compared with placebo in improving symptoms in NUD patients. This study re-emphasizes the good prognosis of patients with NUD, with $14 \%$ of patients improving in the two-week placebo run-in phase and a further $33 \%$ improving in the next six weeks while on placebo. Within-treatment analysis of investigator assessments showed improvement for cisapride $20 \mathrm{mg}$ tid suggesting a trend for efficacy at this dose. (Pour le résumé, voir page 128)

Key Words: Cisapride, Nonulcer dyspepsia, Placebo controlled study

Ottawa Civic Hospital, University of Ottawa, Ottawa, Ontario; Foothills Hospital, University of Calgary, Calgary, Alberta; University of Alberta, Edmonton, Alberta; Halifax Infirmary, Dalhousie University, Halifax, Nova Scotia; Victoria Hospital, University of Western Ontario, London, Ontario; Victoria Hospital, University of Montreal, Montreal, Quebec

Correspondence and reprints: Dr MC Champion, GI Unit A1, Ottawa Civic Hospital, 1053 Carling Avenue, Ottawa, Ontario K1Y 4E9.

Telephone 613-761-4674, fax 613-761-5269 or 613-761-4675, e-mail mchampion@civich.ottawa.on.ca

Received for publication March 2, 1996. Accepted July 5, 1996 


\section{Étude randomisée à double insu sur le cisapride dans le traitement de la dyspepsie non ulcéreuse}

RÉSUMÉ : Le cisapride est une benzamide substitué doté d'effets gastrointestinaux procinétiques que l'on attribue à la stimulation de la libération physiologique d'acétylcholine au niveau du plexus myentérique. Dans une étude multicentrique, 189 patients atteints de dyspepsie non ulcéreuse (DNU) ont reçu un traitement placebo à simple insu pendant deux semaines. Un total de 123 patients ne démontrant aucune réponse ou une réponse minimale au placebo et une douleur épigastrique au moins d'une gravité et d'une fréquence modérées ont été assignés au hasard à l'un des trois traitements en parallèle à double insu pendant six semaines : cisapride $10 \mathrm{mg}$ trois fois par jour, cisapride $20 \mathrm{mg}$ trois fois par jour ou placebo. La gravité et la fréquence des symptômes individuels (douleur épigastrique, brûlures d'estomac, nausées, vomissements, anorexie, malaise postprandial, régurgitation, douleur abdominale basse, ballonnements et constipation) ont été évalués sur une échelle absolue de quatre et cinq points, respectivement, par le chercheur lors de trois visites pendant le traitement et par les patients dans un journal tenu quotidiennement. L'analyse des évaluations des patients et du chercheur pour les différences de gravité des symptômes $\mathrm{X}$ par les scores composés de la fréquence parmi les groupes recevant les trois traitements n'a démontré aucune différence significative sur le plan statistique pour les symptômes individuels ou pour des groupes de symptômes. Tel qu'évalué par le chercheur, et comparé aux valeurs de base, le cisapride à $20 \mathrm{mg}$ trois fois par jour a réduit la douleur épigastrique, les ballonnements et la satiété précoce, de façon significative $(\mathrm{P}<0,05)$, de même qu'il a amélioré l'ensemble des symptômes. L'évaluation par le chercheur des cinq symptômes les plus graves et les plus fréquents pour chaque patient a mis en évidence une amélioration significative sur le plan statistique pour chaque groupe de traitement. Pour les évaluations faites par les patients dans leur propre journal, une amélioration intra-traitement, significative sur le plan statistique, de l'ensemble des symptômes, des cinq symptômes les plus graves du groupe de symptômes, des ballonnements et de la satiété précoce, a été observée avec le cisapride à $20 \mathrm{mg}$ et le placebo, tandis que la douleur épigastrique s'est améliorée de façon significative $(\mathrm{P}<0,05)$ dans les trois groupes de traitement. L'évaluation par le chercheur du taux de réponse global (bonne + excellente) à la fin de la période des six semaines de traitement était de $38 \%$ pour le cisapride à $20 \mathrm{mg}$, de $47 \%$ pour le cisapride à $10 \mathrm{mg}$ et de $33 \%$ pour le placebo. Aucune différence sur le plan statistique n'a été notée dans ce paramètre parmi les traitements. Le cisapride était bien toléré aux deux doses et démontrait un profil d'effets secondaires comparable à celui du placebo. Il a donc été conclu que, dans cette étude multicentrique à double insu avec une phase de préinclusion avec un placebo de deux semaines à simple insu, le cisapride à $10 \mathrm{mg}$ trois fois par jour et à $20 \mathrm{mg}$ trois fois par jour , comparé au placebo, n'était pas efficace pour améliorer les symptômes des patients souffrant de DNU. La présente étude confirme le bon pronostic des patients souffrant de DNU, avec une amélioration des symptômes chez $14 \%$ des patients dans la phase de préinclusion de deux semaines avec un placebo, et avec une amélioration chez $33 \%$ de plus des patients recevant le placebo dans les six semaines suivantes. L'analyse intra-traitement faite par le chercheur a démontré une amélioration des symptômes avec le cisapride à $20 \mathrm{mg}$ trois fois par jour laissant à penser qu'il tend à être efficace à cette dose.
$T_{1}$ he term dyspepsia has been used to describe the symptom-complex epigastric pain that is often associated with other dysmotility symptoms such as nausea, vomiting, regurgitation, heartburn, early satiety and anorexia referable to the upper abdomen (1). Pain, the primary symptom, is usually located in the epigastrium and is often related to eating. Several causes of dyspepsia have been reviewed (2). Nonulcer dyspepsia (NUD) or functional dyspepsia can be more narrowly defined by the above symptom complex together with negative endoscopic or sonographic findings and the absence of pancreatic or hepatic disease.

The pathogenesis of NUD is not well defined and appears to be multifactorial (2-5). Patients with NUD may present with symptoms that fall into one of three distinct patterns (4) that are suggestive of, but not pathognomonic for, underlying etiologies: ulcer-like, dysmotility-like and reflux-like. A fourth group of patients do not fall into any subgroup and are classified as unspecified (6). There has been support for the role of acid in the etiology of NUD even though the basal and peak acid secretion have been shown to be normal (7). The results of studies with acid suppressants have been conflicting $(2,8,9)$ whereas studies with antacids have been universally negative (8-11). Finally, Helicobacter pylori infection (12) and increased levels of gastrointestinal peptide hormones (13) have not been convincingly implicated in the pathogenesis of NUD.

In contrast, there is evidence to suggest that abnormal motility may play a role in the pathogenesis of NUD. Approximately $50 \%$ of patients with dyspeptic symptoms of unknown origin have a motility disturbance, primarily de- layed gastric emptying, pyloroduodenal dysmotility, gastroesophageal dysmotility or antral hypomotility (14-21). Indeed, the majority of symptoms associated with NUD are suggestive of disturbed motility in the upper gastrointestinal tract. There exists, therefore, a strong rationale for the use of prokinetic agents in NUD, particularly when symptoms at presentation are primarily motility- or reflux-related. In general, clinical studies with metoclopramide, domperidone or cisapride in NUD patients have been positive. Analysis of these data indicates a large variability in patient selection which makes it difficult to interpret results and conclusions in the context of North American patient care (9).

The pharmacological profile of cisapride suggests possible efficacy in NUD, and for this reason this Canadian study was undertaken.

\section{PATIENTS AND METHODS}

Trial design: A total of 189 patients with NUD satisfying the selection criteria given below were selected for participation in a fixed-dose, parallel group design, double-blind, placebo controlled clinical trial at six Canadian research centres. Each subject provided written informed consent before participation. The study was carried out in accordance with the current revision of the Declaration of Helsinki and was approved by the ethics review committee at each centre. Patients entered a two-week, single-blind run-in period during which they evaluated their symptoms daily. Nonresponders (defined below) to this placebo treatment were randomly and equally assigned to one of three treatments for six weeks: cisapride $10 \mathrm{mg}$ tid, cisapride $20 \mathrm{mg}$ tid or placebo. All medi- 
cations were given $0.5 \mathrm{~h}$ before meals. Once treatment with study medication began, no other medication that could interfere with the assessment of the study drug, including domperidone, metoclopramide, $\mathrm{H}_{2}$ antagonists, prostaglandins, sucralfate, major tranquilizers, antidepressants, antiemetics or (anti)cholinergics, was allowed except for aluminum hydroxide in the case of severe gastrointestinal symptoms requiring a 'rescue' medication.

Demographic information and disease history were obtained at screening. Patients were evaluated by the investigator for efficacy (investigator ratings of the severity and frequency of individual symptoms) and safety at baseline and at weeks 2, 4 and 6. Patients kept daily symptom severity assessment diaries throughout the trial. Laboratory parameters and physical examination were assessed pre- and posttreatment; vital signs and any adverse experiences reported were recorded at each visit.

Patient selection: Male and female patients, aged 18 to 70 years, presenting with epigastric pain that was of moderate or greater severity, had been episodic in frequency over the past two years and was usually related to meals were eligible for entry into the trial. Symptoms had to have been present for at least four weeks before selection. Patients were required to have had an endoscopy that was negative for peptic ulcer disease within the previous two weeks; a biopsy for $\mathrm{H}$ pylori was optional and was performed on 92 of the 123 evaluable patients. An upper abdominal ultrasound was required to have been negative for pancreatic and biliary tract disease within the previous three months. Patients who had had gastrointestinal surgery other than appendectomy, cholecystectomy or inguinal hernia repair were excluded, as were patients with gastric outlet obstruction. Patients with active disease (eg, radiologically or endoscopically proven ulcer in the past year, cholelithiasis, pancreatic or hepatic disease), a history of medication use (eg, nonsteroidal anti-inflammatory drugs, calcium channel blockers, L-dopa) or any other condition (eg, alcohol abuse) that could account for their dyspeptic symptoms were excluded. Clinically significant renal, cardiovascular, psychiatric, malignant and neurological diseases were excluded, and results from biochemical and hematological laboratory tests had to have been within normal limits at screening. Pregnant or lactating women or women without adequate contraception were excluded. Patients meeting all the above criteria who completed the two-week single-blind placebo run-in period with epigastric pain of moderate or greater severity occurring at least three to six times per week were randomized to double-blind treatment.

Efficacy evaluation: Investigators rated symptom severity using the following four-point categorical scale: $0=$ none; $1=$ mild (aware of symptoms but may require prompting to recall; pain does not interfere with daily activity or sleep); 2 = moderate (volunteers information, symptoms interfere with daily activities or awaken patient briefly from sleep); or 3 = severe (daily routine is no longer possible and/or sleep is disturbed regularly). Symptom frequency was rated using the following five-point categorical scale: $0=$ none; 1 = occa- sional; 2 = often (three to six days/week); 3 = frequent (daily); or $4=$ chronic (all the time). The following 10 symptoms were evaluated: epigastric pain, retrosternal pain, nausea, vomiting, anorexia, early satiety, regurgitation, lower abdominal pain (cramping), bloating and constipation. For purposes of analysis and presentation, a combined score was calculated for each patient at each visit by multiplying the severity and frequency scores for each symptom; the resulting symptom score ranged from 0 to 12 . The symptom product scores were skewed towards very mild severity and low frequency at baseline; with the exception of epigastric pain, which was preselected by the entry criteria to have a minimum score of 4 out of a possible 12 , the symptom product scores in the majority of patients were less than 6 at entry. This trend in the data distribution strengthened across the trial as symptoms improved. To provide a meaningful categorization of each parameter at baseline and across the trial the midpoint of each symptom product score distribution was determined and the symptoms were rated as less than or equal to the midpoint ('yes' or 'no'), creating a binomial response for analysis. A 'total' symptom cluster was created by summing all 10 symptom product scores (range 0 to 120). A 'top five' symptom cluster (range 0 to 60 ) was created for each patient by summing the five highest (most severe and frequent) combined symptom scores presented at baseline by each patient.

Patients rated the following eight symptoms - fullness or discomfort after meals (early satiety), poor appetite (anorexia), epigastric pain, nausea, heartburn, regurgitation, bloating and lower abdominal pain (cramping) - each day as none (0) , mild (1), moderate (2) or severe (3). These severity ratings were summed across a standardized 14-day period, corresponding to the time between each visit, to derive a summary measure for each patient symptom (range 0 to 42 ) at each visit. Total and top five symptom clusters were calculated for each patient in the same manner as described above for the investigator ratings.

At the end of the study the investigator and each patient rated the overall response to treatment on a five-point categorical scale: excellent (complete relief of symptoms), good (improvement with only occasional symptoms), fair (slight improvement, persistence of some symptoms), poor (no improvement) or deteriorated (symptoms worse).

Statistical methods: The level of significance was set at 0.05 , two-tailed, for all analyses. Comparisons were made among the three treatment groups to assess the homogeneity of the demographic parameters. Categorical data were analyzed using Pearson's $\chi^{2}$ test, or where the data were sparse, the extended Fisher's exact test, while a one-way ANOVA tested the continuous parameters. The individual investigatorassessed symptoms were analyzed and displayed as categorical data. The differences among the treatment groups in the frequency of the binomial response (above midpoint: yes or no) were assessed at baseline for each investigator symptom using Pearson's $\chi^{2}$ test; the analysis at week 6 was performed using logistic regression to assess the effect of treatment, baseline score, duration of NUD and duration of present 
TABLE 1

\section{Patient demographics}

\begin{tabular}{lccc}
\hline Parameter & $\begin{array}{c}\text { Cisapride } \\
\mathbf{2 0 ~} \mathbf{~ m g}\end{array}$ & $\begin{array}{c}\text { Cisapride } \\
\mathbf{1 0} \mathbf{~ m g}\end{array}$ & Placebo \\
\hline \# of subjects & 42 & 41 & 40 \\
Age (years) & 40.8 & 40.0 & 41.5 \\
Sex (male:female) & $13: 29$ & $12: 29$ & $13: 27$ \\
Weight (kg) & 64.7 & 65.0 & 66.5 \\
NUD duration (years) & 7.0 & 5.4 & 6.8 \\
Helicobacter pylori & $5(11.9)$ & $4(9.7)$ & $4(10.0)$ \\
$\quad$ histology positive: \# (\%) & & & \\
Symptom duration (months) & 11.8 & 6.7 & 10.8 \\
Smoker: \# (\%) & $5(11.9)$ & $13(31.7)$ & $13(32.5)$ \\
Coffee/tea/carbonated & $33(70.5)$ & $36(87.8)$ & $33(82.5)$ \\
$\quad$ drink: \# (\%) & & & \\
Alcohol consumption: \# (\%) & $21(50.0)$ & $21(51.2)$ & $19(47.5)$ \\
\hline
\end{tabular}

NUD Nonulcer dyspepsia

symptoms on the week 6 binomial response. Within-treatment binomial changes from baseline to week 6 were analyzed using the categorical linear model with a marginal probability option. Total and top five investigator symptom clusters, as well as all the patient daily diary data, were analyzed and presented as parametric data. The one-way ANOVA was employed to detect statistically significant differences among the treatments at baseline for these parameters, while an analysis of covariance using the baseline as the covariate detected differences among the treatment



Figure 1a) Investigator assessment: Frequency $x$ severity scores at baseline groups in the change from baseline score. Patient and physician global evaluation end-of-treatment ratings were analyzed using the Cochran Mantel-Haenszel $\chi^{2}$ test with the modified ridit option, to focus on the implied order of the responses.

\section{RESULTS}

Patient characteristics and attrition: A total of 189 patients were selected at the six study centres; individual centre enrolment ranged from 16 to 53 patients. Of the 189 patients, $123(65.1 \%)$ met the post-run-in period criteria for randomization and were allocated to treatment as follows: cisapride $20 \mathrm{mg}$ tid $(\mathrm{n}=42)$, cisapride $10 \mathrm{mg}$ tid $(\mathrm{n}=41)$ and placebo $(n=40)$. Twenty-seven subjects did not complete the full six-week double-blind treatment; the number of patients discontinuing the study prematurely was comparable among treatment groups. Reasons for early withdrawal from the study were request to be withdrawn $(n=10)$; medical condition adversely affected by trial conditions $(n=8)$; noncompliance $(n=6)$; adverse events $(n=1)$; follow-up $(n=1)$; and other $(n=1)$. All 123 randomized patients were included in the intention-to-treat efficacy and safety analyses.

The average age of patients was 41 years and there were more females $(69.1 \%)$ than males. The mean duration of NUD was 6.4 years and of present symptoms was 9.8 months. Histology for $\mathrm{H}$ pylori was positive for $14.1 \%$ of patients. There were no differences among the treatment groups for any of the demographic parameters (Table 1).

$\chi^{2}$ analysis of the baseline symptom binomial response



Figure 1b) Patient daily diary: Distribution of mean frequency $x$ severity scores at baseline 


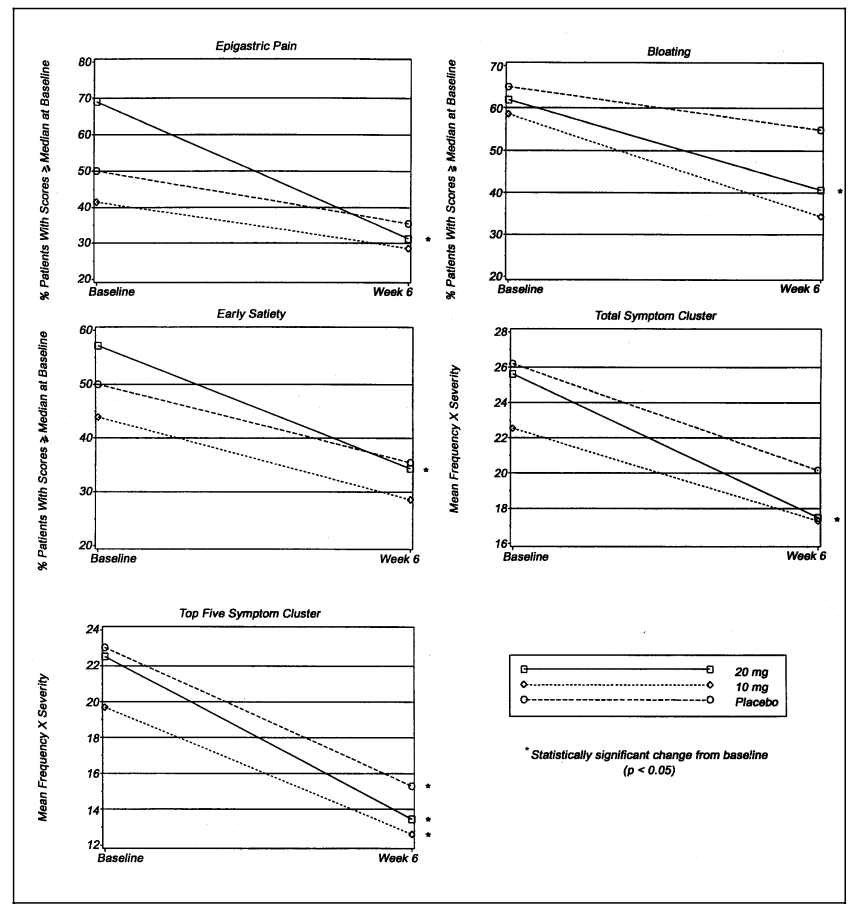

Figure 2a) Investigator assessment: Frequency $x$ severity

yielded a statistically significant difference among the three treatments for investigator-rated epigastric pain $(\mathrm{P}=0.036)$; the $20 \mathrm{mg}$ cisapride patients were rated more frequently above the overall midpoint. One-way ANOVA indicated statistically significant differences among the treatments for patient-rated epigastric pain $(\mathrm{P}=0.0061)$ and early satiety $(\mathrm{P}=0.0418)$, with the placebo group having more severe ratings for both parameters. No other differences were detected at baseline. As a general trend, the highest baseline ratings overall were observed primarily in the placebo group and the most mild and infrequent symptoms at baseline were manifest in patients treated with cisapride $10 \mathrm{mg}$ (Figure 1). Symptom evaluation: No statistically significant amongtreatment differences in symptom severity $\mathrm{x}$ frequency product scores were found for either patient- or investigatorassessed individual symptoms or symptom clusters among the three treatment groups.

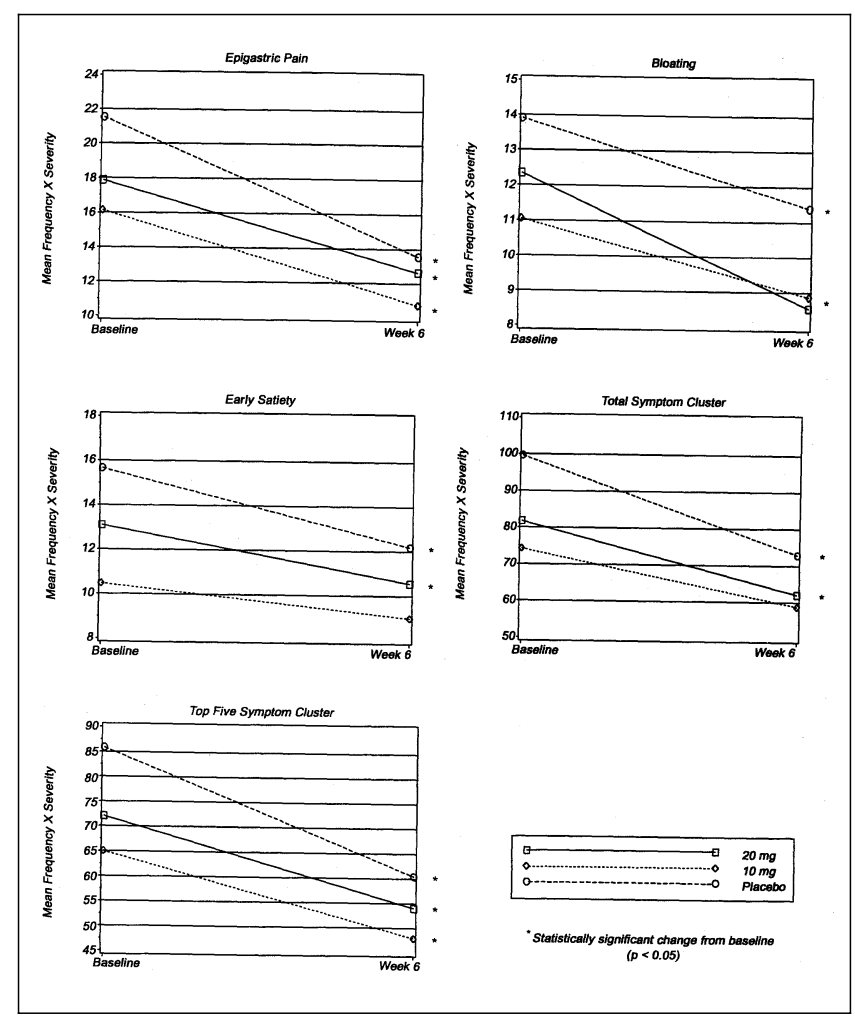

Figure 2b) Patient daily diary: Frequency $x$ severity

Analysis of investigator-rated individual symptoms indicated a statistically significant reduction from baseline to week 6 for the $20 \mathrm{mg}$ cisapride group only in the proportion of patients rated with more severe epigastric pain $(\mathrm{P}<0.0001)$, bloating $(\mathrm{P}=0.0229)$, early satiety $(\mathrm{P}=0.0008)$ and total symptom cluster $(\mathrm{P}=0.0003)$. The covariate baseline was also significant $(\mathrm{P}<0.01)$ for each of these parameters, except total symptom cluster which indicated a strong predictive role for baseline scores. Figure 2A displays these results and supports the observation that the strongest responses to treatment were consistently observed in the cisapride $20 \mathrm{mg}$ group. Analysis of the top five symptom cluster indicated that the covariate baseline was not significant, while all three treatment groups displayed a statistically significant decrease from baseline to week 6 (Table 2).

TABLE 2

Investigator assessments

\begin{tabular}{|c|c|c|c|c|c|c|c|c|c|}
\hline \multirow[b]{3}{*}{ Symptom* } & \multicolumn{3}{|c|}{ Cisapride 20 mg } & \multicolumn{3}{|c|}{ Cisapride $10 \mathrm{mg}$} & \multicolumn{3}{|c|}{ Placebo } \\
\hline & \multirow{2}{*}{$\begin{array}{c}\text { Baseline } \\
\text { n (\%) }\end{array}$} & \multicolumn{2}{|c|}{ Week 6} & \multirow{2}{*}{$\begin{array}{c}\text { Baseline } \\
\text { n (\%) }\end{array}$} & \multicolumn{2}{|c|}{ Week 6} & \multirow{2}{*}{$\begin{array}{c}\text { Baseline } \\
\text { n (\%) }\end{array}$} & \multicolumn{2}{|c|}{ Week 6} \\
\hline & & n (\%) & $\mathbf{P}$ & & n (\%) & $\mathbf{P}$ & & n (\%) & $\mathbf{P}$ \\
\hline Bloating & $26(61.9)$ & $13(40.6)$ & $0.0229^{* *}$ & $24(58.5)$ & $12(34.3)$ & 0.0763 & $26(65.0)$ & $17(54.3)$ & 0.1173 \\
\hline Early satiety & $24(57.1)$ & $11(34.4)$ & $0.0008^{* *}$ & $18(43.9)$ & $10(28.6)$ & 0.1954 & $20(50.0)$ & $11(35.5)$ & 0.0684 \\
\hline Total & $25.6 \pm 16.0$ & $17.5 \pm 13.5$ & $0.0003^{* *}$ & $22.5 \pm 12.9$ & $17.3 \pm 17.3$ & 0.0783 & $26.2 \pm 14.3$ & $20.2 \pm 21.3$ & 0.0536 \\
\hline Top five & $22.5 \pm 11.3$ & $13.4 \pm 10.7$ & $0.0001^{* *}$ & $19.7 \pm 10.0$ & $12.6 \pm 12.6$ & $0.0018^{\star *}$ & $23.0 \pm 10.7$ & $15.3 \pm 14.2$ & $0.0011^{\star *}$ \\
\hline
\end{tabular}

${ }^{*}$ Presented as frequency of symptom severity $x$ frequency score $\geq$ median baseline score; ${ }^{*}$ Statistically significant change from baseline $(P<0.05) ;{ }^{\dagger}$ Presented as mean symptom severity $x$ frequency score 
TABLE 3

Patient daily diary results

\begin{tabular}{|c|c|c|c|c|c|c|c|c|c|}
\hline \multirow[b]{3}{*}{ Symptom } & \multicolumn{3}{|c|}{ Cisapride 20 mg } & \multicolumn{3}{|c|}{ Cisapride 10 mg } & \multicolumn{3}{|c|}{ Placebo } \\
\hline & \multirow{2}{*}{$\begin{array}{c}\text { Baseline } \\
\text { Mean } \pm \text { SD }\end{array}$} & \multicolumn{2}{|c|}{ Week 6} & \multirow{2}{*}{$\begin{array}{c}\text { Baseline } \\
\text { Mean } \pm \text { SD }\end{array}$} & \multicolumn{2}{|c|}{ Week 6} & \multirow{2}{*}{$\begin{array}{c}\text { Baseline } \\
\text { Mean } \pm \text { SD }\end{array}$} & \multicolumn{2}{|c|}{ Week 6} \\
\hline & & Mean \pm SD & $\mathbf{P}$ & & Mean \pm SD & $\mathbf{P}$ & & Mean \pm SD & $\mathbf{P}$ \\
\hline Epigastric pain & $17.9 \pm 7.6$ & $12.6 \pm 13.5$ & $0.0044^{* *}$ & $16.1 \pm 6.6$ & $10.7 \pm 10.5$ & $0.0036^{* *}$ & $21.5 \pm 8.3$ & $13.6 \pm 11.8$ & $0.0001^{* *}$ \\
\hline Bloating & $12.3 \pm 10.4$ & $8.5 \pm 10.6$ & $0.0371^{* *}$ & $11.0 \pm 8.5$ & $8.9 \pm 9.9$ & 0.2588 & $13.9 \pm 11.7$ & $11.4 \pm 11.9$ & $0.0431^{* *}$ \\
\hline Early satiety & $13.1 \pm 7.4$ & $10.5 \pm 9.1$ & $0.0361^{* *}$ & $10.5 \pm 7.2$ & $9.0 \pm 9.6$ & 0.2912 & $15.7 \pm 11.9$ & $12.2 \pm 12.3$ & $0.0186^{* *}$ \\
\hline Symptom clusters ${ }^{*}$ & Mean \pm SD & Mean \pm SD & $\mathbf{P}$ & Mean \pm SD & Mean \pm SD & $\mathbf{P}$ & Mean \pm SD & Mean \pm SD & $\mathbf{P}$ \\
\hline
\end{tabular}

${ }^{*}$ Presented as mean symptom severity $x$ frequency score; * Statistically significant change from baseline $(P<0.05)$

The unique significant within-treatment effect observed for the $20 \mathrm{mg}$ cisapride group for investigator assessments was not replicated in the analysis of patient daily diary scores (Figure 2B). For epigastric pain, a significant reduction in symptom severity scores from baseline to the final treatment day was observed in patients treated with placebo $(\mathrm{P}=0.0001)$, cisapride $10 \mathrm{mg}(\mathrm{P}=0.0036)$ and cisapride $20 \mathrm{mg}(\mathrm{P}=0.0044)$. For early satiety and bloating, as well as the total and top five symptom clusters, statistically significant within-treatment effects were found for both cisapride $20 \mathrm{mg}$ and placebo (Table 3 ).

The percentage of patients who rated their overall response to treatment as 'good' or 'excellent' at the last study visit was $45 \%$ for the cisapride $20 \mathrm{mg}$ group, $52 \%$ for cisapride $10 \mathrm{mg}$ and $36 \%$ for placebo. Global response rated by investigators demonstrated a similar trend (38\% for cisapride $20 \mathrm{mg}$, 47\% for cisapride $10 \mathrm{mg}$ and $33 \%$ for placebo). None of the differences among treatments in the global response ratings was statistically significant. Post-hoc power analysis of the global evaluation, the parameter on which the sample size was estimated, yielded the following results. The percentage power to detect a difference versus placebo in the investigator evaluation of overall response was $7 \%$ and $25 \%$ for cisapride $20 \mathrm{mg}$ and $10 \mathrm{mg}$, respectively. Similar low levels of power were estimated for patient ratings: $13 \%$ (placebo versus cisapride $20 \mathrm{mg}$ ) and $32 \%$ (placebo versus cisapride $10 \mathrm{mg}$ ).

There were 149 adverse events reported during the study; $60(40.3 \%)$ were reported during the placebo run-in phase and 89 during the double-blind treatment phase. Of the 89 events occurring during the double-blind phase, 38 reports $(42.7 \%)$ were from the cisapride $10 \mathrm{mg}$ group, 32 (36.0\%) from the cisapride $20 \mathrm{mg}$ group and $19(21.3 \%)$ from the placebo group. These 89 adverse events were reported by 36 patients: $14(31.8 \%)$ from those on cisapride $10 \mathrm{mg}, 10$ (29.4\%) from those on cisapride $20 \mathrm{mg}$ and 12 (26.1\%) from those on placebo. Headache was the most common adverse event reported by nine $(20.5 \%)$ patients assigned to cisapride $10 \mathrm{mg}$, three $(6.7 \%)$ assigned to cisapride $20 \mathrm{mg}$ and five $(10.9 \%)$ assigned to placebo. Other adverse events occurring in cisapride-treated patients and reported by at least two subjects were abdominal pain, nausea, insomnia, constipation and dizziness.

\section{DISCUSSION}

This study was designed to compare the efficacy and tolerability of cisapride with placebo in placebo-nonresponsive patients with NUD, and to examine possible dose-response relationships for optimal therapeutic effect. The main finding of this clinical trial was that response to cisapride treatment at either dose ( $10 \mathrm{mg}$ tid or $20 \mathrm{mg}$ tid) failed to demonstrate any statistically significant difference from placebo. Careful examination of the data and critical analysis of the methodological features of this and other studies in NUD patients reveal several possible explanations for this negative result.

With respect to data-driven causes, perhaps the most compelling involves the distribution of symptom scores at baseline. At selection, symptom severity was universally mild and frequency was universally low as illustrated in Figure 1. This mild presentation of symptom scores at entry makes it difficult to demonstrate statistically significant improvement over time and suggests that a decrease from baseline would more likely be detected for treatment groups and symptoms that have higher scores at baseline. Indeed, this hypothesis is borne out by the preponderance of significance for baseline as a predictor of change. Moreover, as Figure 2 illustrates, treatment groups consistently differed with respect to their baseline scores with the general trend for the most severe and/or frequent symptoms upon entry in the placebo group, and occasionally the cisapride $20 \mathrm{mg}$ group, and the most mild and/or infrequent symptoms in the cisapride $10 \mathrm{mg}$ group for both patient and investigator ratings. These baseline imbalances were often statistically significant, particularly in patient symptom assessments. Considering the predictive value of baseline scores, one can speculate that the high degree of placebo response observed was at least partially attributable to a 'regression towards the mean' phenomenon. This concept is supported by our results depicted in Figure 2. The similarity in end-of-treatment scores for both cisapride groups is evident, and scores for both doses are usually separated from placebo. However, significant withintreatment differences are observed for only the cisapride $20 \mathrm{mg}$ group, possibly because of the low baseline severity and frequency scores of the $10 \mathrm{mg}$ group.

The relatively high overall response to placebo (33\% to $36 \%$ ) despite the inclusion of the single-blind placebo run-in period is also of interest. NUD is typically a chronically relaps- 
ing and remitting disorder, and patients seek medical attention when the symptoms are usually most severe and troublesome (3). These conditions of patient behaviour are conducive to the promotion of a placebo response secondary to spontaneous improvement. Moreover, evidence suggests that both the undertaking and quality of the physician-patient relationship are of greatest importance in facilitating the placebo response (3) and, thus, a considerable so-called 'trial effect' is feasible. Given that placebo responses are generally acute in nature, it would be of interest to conduct a study of longer duration, for example, six months, to ascertain whether the placebo response would be subject to a 'wearing-off phenomenon. Examination of results from the present study (Figure 2) suggest some trend for separation of active treatments from placebo towards the end of the six-week treatment period. Finally, the substantive placebo response combined with the relatively small number of patients, which decreased by $22 \%$ over the course of the study, and wide variability in the data observed (as evidenced by the large standard deviations), all likely contributed to the lack of statistical power (post-hoc power estimates ranging from $7 \%$ to $32 \%$ ). It would have required a sample size of at least 129 evaluable patients per treatment group to rule out a type 2 error $(\mathrm{P}=0.8)$.

Related to these issues are a number of study methodological factors that may have additionally confounded the ability of this study to detect an effect of active treatment over placebo. The most salient is the heterogeneity of NUD in terms of both its pathophysiology and clinical presentation (1-5). NUD is, by definition, a diagnosis of exclusion and has been and continues to be the subject of considerable controversy. Moreover, a scientific basis for a definitive subclassification of NUD remains to be established. Indeed, NUD has not yet been recognized by the United States Food and Drug Administration and Canadian Health Protection Branch, and no drug is currently approved for use in NUD in North America. This broad and nonspecific definition of NUD complicates the selection of patients into NUD drug studies; large interstudy variation in the definition of patient samples is likely to be largely responsible for the contradictory results observed across trials.

In the present study it is possible that a negative selection bias occurred for several reasons. First, the investigators comprised a group of specialists in gastroenterology practising in tertiary care settings. Given the structure and function of the Canadian health care system, only the more severe and/or unresponsive patients would tend to be referred to the specialist. Second, patients relieved by nonprescription proprietary medication are less likely to seek medical advice and therefore to be included in drug trials; this study sample may thus have constituted a selection of nonresponders to drug therapy. Third, this protocol required a prestudy endoscopy and ultrasonography. This could mean that only the more severe and/or refractory patients would be included.

An additional factor related to patient sample selection is the purported psychogenic causative component of this illness $(22,23)$. In the current study psychosocial issues were not evaluated and no inventory of affective symptoms, such as depression or anxiety, was obtained. In addition, patients were selected for inclusion in this study on the basis of the existence of at least moderately severe and frequent epigastric pain, the disease-defining symptom for NUD. Perhaps patients with more motility-related symptoms would have yielded more positive results in this study of cisapride. However, a post-hoc analysis using empiric definitions for different subtypes of NUD was performed and revealed no major differences with the main analysis. Finally, with respect to patient selection, the lack of statistical difference among groups in the $75 \%$ of patients in whom the existence of $H$ pylori was checked by biopsy at screening confirms that the treatment of $H$ pylori infection has not been implicated in the medical management of NUD (12).

The final methodological issue in NUD studies is the means of assessing symptom improvement. Previous studies have frequently relied solely on a global investigation or patient evaluation to demonstrate efficacy (9). This study used both a regular investigator evaluation and a daily patient symptom diary together with global evaluation. The discordance in the results among these methods of evaluating symptom improvement raises the question of which is the most reliable or accurate method for evaluating symptom improvement in clinical studies.

As mentioned earlier, the literature is replete with conflicting study reports for any chosen pharmacological intervention in NUD; this literature has been comprehensively reviewed $(2,4,9)$. Several studies with antacids have demonstrated that symptom relief was no different from placebo $(24,25)$. Results reported in the literature on clinical trials with $\mathrm{H}_{2}$-receptor antagonists in NUD are contradictory, with only approximately half the studies showing significant improvement over placebo $(8,24)$. Clinical studies performed with the prokinetic agents metoclopramide (26-28) and domperidone $(29,30)$ have shown symptomatic improvement over placebo in all but one report (31). Clinical trials with cisapride $(19,20,32-35)$ in doses ranging from $4 \mathrm{mg}$ tid to $10 \mathrm{mg}$ tid have consistently demonstrated improvements that usually achieved statistical significance over placebo (32-35). In contrast, negative results have also been reported in some studies of cisapride $(19,20)$, perhaps due to the small number of subjects studied. That the cisapride $10 \mathrm{mg}$ group did not quantitatively or qualitatively demonstrate symptom improvement could simply be dose-related and indicate that, based on results from the present study, the preferred dose of cisapride to treat NUD is $20 \mathrm{mg}$ tid. This, however, is difficult to reconcile with results from previously published papers that have shown positive results with cisapride doses administered at $4 \mathrm{mg}$ tid to $10 \mathrm{mg}$ tid (32-35). Most important, the considerable variation in the design and execution of drug trials in NUD calls for a high degree of critical review when interpreting and comparing their results.

\section{CONCLUSION}

This study demonstrates the importance of including a placebo group in clinical studies evaluating the efficacy of pharmacological agents in patients with motility disorders. 
Despite a single-blind two-week placebo run-in period, cisapride $10 \mathrm{mg}$ tid or $20 \mathrm{mg}$ tid was not effective compared with placebo in improving symptoms in NUD patients. Within-treatment analysis of investigator assessments showed improvements for cisapride $20 \mathrm{mg}$ tid, suggesting a trend for efficacy at this dose. Despite these results there may be a subgroup of patients with NUD not identified by this study who may respond to a prokinetic agent. Further studies with prokinetic agents in patients with dyspepsia associated with other motility symptoms should resolve this question.

ACKNOWLEDGEMENTS: The authors thank Anna Micucci for her secretarial assistance, Dr W Arnott and Dr R Treffers for their technical assistance in analysis of the data, and Ms Janet McDougall of McDougall Scientific Toronto for her statistical analysis of the data.

\section{REFERENCES}

1. Horrocks JC, de Dombal FT. Clinical presentation of patients with dyspepsia. Detailed symptomatic study of 360 patients. Gut 1978;19:19-26.

2. Thompson WG. Non-ulcer dyspepsia. Can Med Assoc J 1984;130:545-9.

3. Talley NJ. Nonulcer dyspepsia: Current approaches to diagnosis and management. Am Fam Physician 1993;47:1407-16.

4. Talley NJ, Colin-Jones D, Koch KL, Koch M, Nyren O, Stanghellini V. Functional dyspepsia: a classification with guidelines for diagnosis and management. Gastroenterol Int 1991;4:145-60.

5. Talley NJ, Phillips SF. Non-ulcer dyspepsia: potential causes and pathology. Ann Intern Med 1988;108:865-79.

6. Colin-Jones DG. Management of dyspepsia: Report of a working party. Lancet 1988;ii:576-9.

7. Collen MJ, Loebenberg MJ. Basal gastric acid secretion in nonulcer dyspepsia with or without duodenitis. Dig Dis Sci 1989;34:246-50.

8. Saunders JHB, Oliver JF, Higson DL. Dyspepsia: incidence of non-ulcer disease in a controlled trial of ranitidine in general practice. BMJ 1986;292:665-8.

9. Talley NJ. Drug treatment of functional dyspepsia. Scand J Gastroenterol 1991;26:47-60.

10. Gotthard R, Bodemar G, Brodin U, Jönsson K-A. Treatment with cimetidine, antacid or placebo in patients with dyspepsia of unknown origin. Scand J Gastroenterol 1988;23:7-18.

11. Talley NJ, McNeil D, Hayden A, Piper DW. Randomized, double-blind, placebo-controlled crossover trial of cimetidine and pirenzepine in nonulcer dyspepsia. Gastroenterology 1986;91:149-56.

12. Talley NJ. A critique of therapeutic trials in Helicobacter pylori-positive functional dyspepsia. Gastroenterology 1994;106:1174-83.

13. Watson RG, Shaw C, Buchanan KD, Love AH. Circulating gastrointestinal hormones in patients with flatulent dyspepsia with and without gallbladder disease. Digestion 1986;35:211-6.

14. Talley NJ. Non-ulcer dyspepsia: myths and realities. Aliment Pharmacol Ther 1991;5(Suppl 1):145-62.

15. Camilleri M, Malagelada JR, Kao PC, et al. Gastric and automonic responses to stress in functional dyspepsia. Dig Dis Sci 1986;31:1169-77.
16. Malagelada J-R, Stanghellini V. Manometric evaluation of functional upper gut symptoms. Gastroenterology 1985:89;1223-31.

17. Geldof H, van der Schee EJ, van Blankenstein M, et al. Electrogastrographic study of gastric myoelectrical activity in patients with unexplained nausea and vomiting. Gut 1986;27:799-808.

18. You CH, Lee KY, Menguy R. Electrogastrographic study of patients with unexplained nausea, bloating and vomiting. Gastroenterology 1980;79:311-3.

19. Corinaldesi R, Stanghellinia V, Raiti C, et al. Effect of chronic administration of cisapride on gastric emptying of solid meal and on dyspeptic symptoms in patients with non-ulcer dyspeptic symptoms in patients with non-ulcer gastroparesis. Gut 1987;28:300-5.

20. Jian R, Ducrot F, Ruskone A, et al. Symptomatic radionuclide and therapeutic assessment of chronic idiopathic dyspepsia: a doubleblind placebo-controlled evaluation of cisapride. Dig Dis Sci 1989;34:657-64.

21. Wegener M, Borsch G, Schaffstein J, et al. Are dyspeptic symptoms in patients with Campylobacter pylori-associated type B gastritis linked to delayed gastric emptying? Am J Gastroenterol 1988;83:737-40.

22. Talley NJ, McNeil D, Hayden A, Colreavy C, Piper DW. Prognosis of chronic unexplained dyspepsia: a prospective study of potential predictor variables in patients with endoscopically diagnosed NUD. Gastroenterology 1987;93:1060-6.

23. Talley NJ, Piper DW. A prospective study of social factors and major life event stress in patients with dyspepsia of unknown cause. Scand J Gastroenterol 1987;22:268-72.

24. Nyrén O, Adami H-O, Bates S, et al. Absence of therapeutic benefit from antacids or cimetidine in nonulcer dyspepsia. N Engl J Med 1986;314:339-43.

25. Weberg R, Berstad A. Low-dose antacids and pirenzepine in the treatment of patients with non-ulcer dyspepsia and erosive prepyloric changes. A randomized, double-blind, placebo-controlled trial. Scand J Gastroenterol 1988;23:237-43.

26. Johnson G. Controlled trial of metoclopramide in the treatment of flatulent dyspepsia. BMJ 1971;ii:25-6.

27. De Loose F. Domperidone in chronic dyspepsia: a pilot open study and a multicentre general practice crossover comparison with metoclopramide and placebo. Pharmatherapeutica 1979;2:140-6.

28. Perkel MS, Moore C, Hersh T, Davidson ED. Metoclopramide therapy in patients with delayed gastric emptying: A randomized, double-blind study. Dig Dis Sci 1979;24:662-6.

29. Van Ganse W, Van Damme L, Van de Mierop L, Deruyttere M, Lauwers W, Coenegrachts J. Chronic dyspepsia: double-blind treatment with domperidone (R33812) or a placebo. A multi-centre therapeutic evaluation. Curr Ther Res 1978;23:695-701.

30. Davis RH, Clench MH, Mathias JR. Effects of domperidone in patients with chronic unexplained upper gastrointestinal symptoms; a double-blind, placebo-controlled study. Dig Dis Sci 1988;33:1505-11.

31. Nagler J, Miskovitz P. Clinical evaluation of domperidone in the treatment of chronic post-prandial idiopathic upper gastrointestinal distress. Am J Gastroenterol 1981;76:495-9.

32. Rösch W. Cisapride in non-ulcer dyspepsia. Results of a placebo-controlled trial. Scand J Gastroenterol 1987;22:161-4.

33. Coutant G, François I, DeNutte N, DeCock G, Borgers P, Rutgeerts L. Dose response study of cisapride in the management of non-ulcer dyspepsia. Prograd Med 1987;43(Suppl 1):91-6.

34. Deruyttere M, Milo R, Creytens G, Goethals C, Bourgeois E, Offner E. Therapy of chronic functional dyspepsia: multicenter crossover study of cisapride and placebo. Prograd Med 1987;43(Suppl 1):61-8.

35. Van Outryve M, De Nutte N, Van Eeghem P, Gooris JP. Efficacy of cisapride in functional dyspepsia resistant to domperidone or metoclopramide: a double-blind, placebo-controlled study. Scand J Gastroenterol 1993;28(Suppl 195):47-53. 


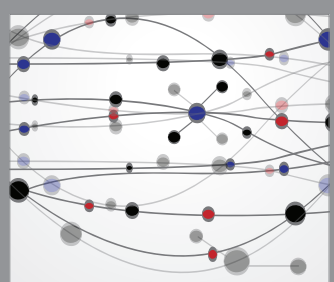

The Scientific World Journal
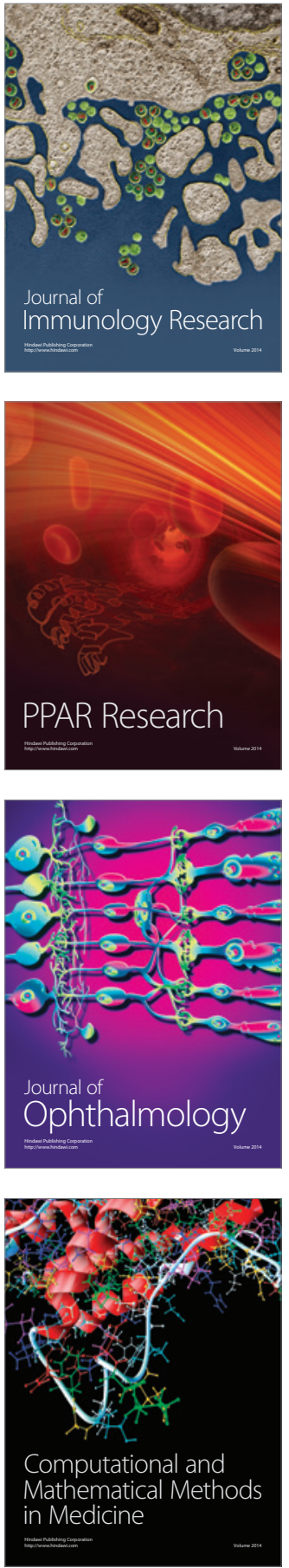

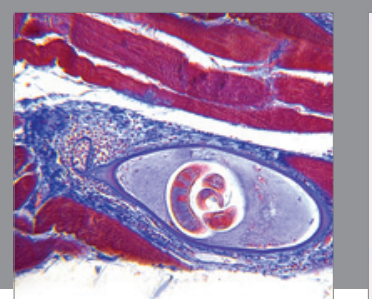

Gastroenterology Research and Practice

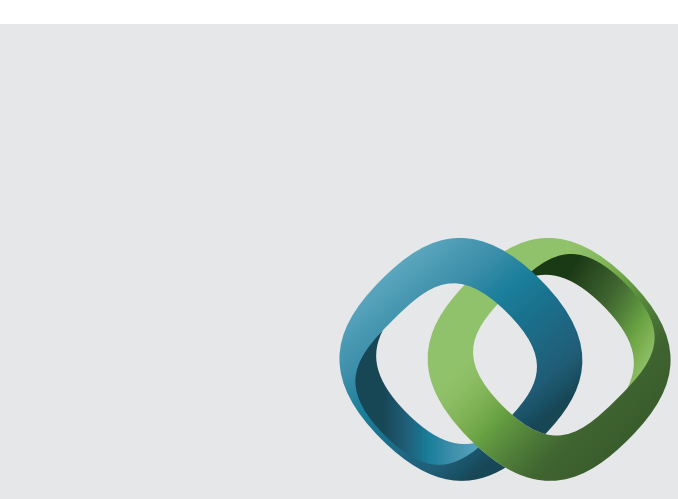

\section{Hindawi}

Submit your manuscripts at

http://www.hindawi.com
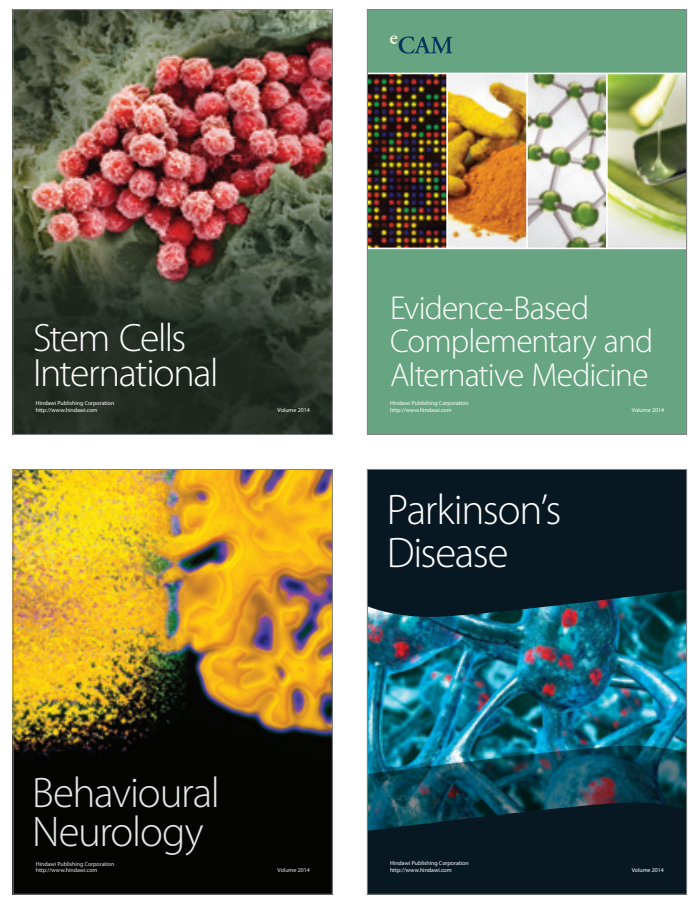
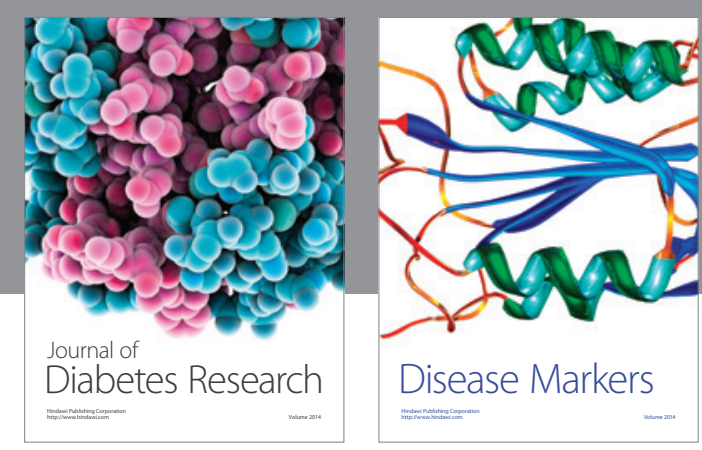

Disease Markers
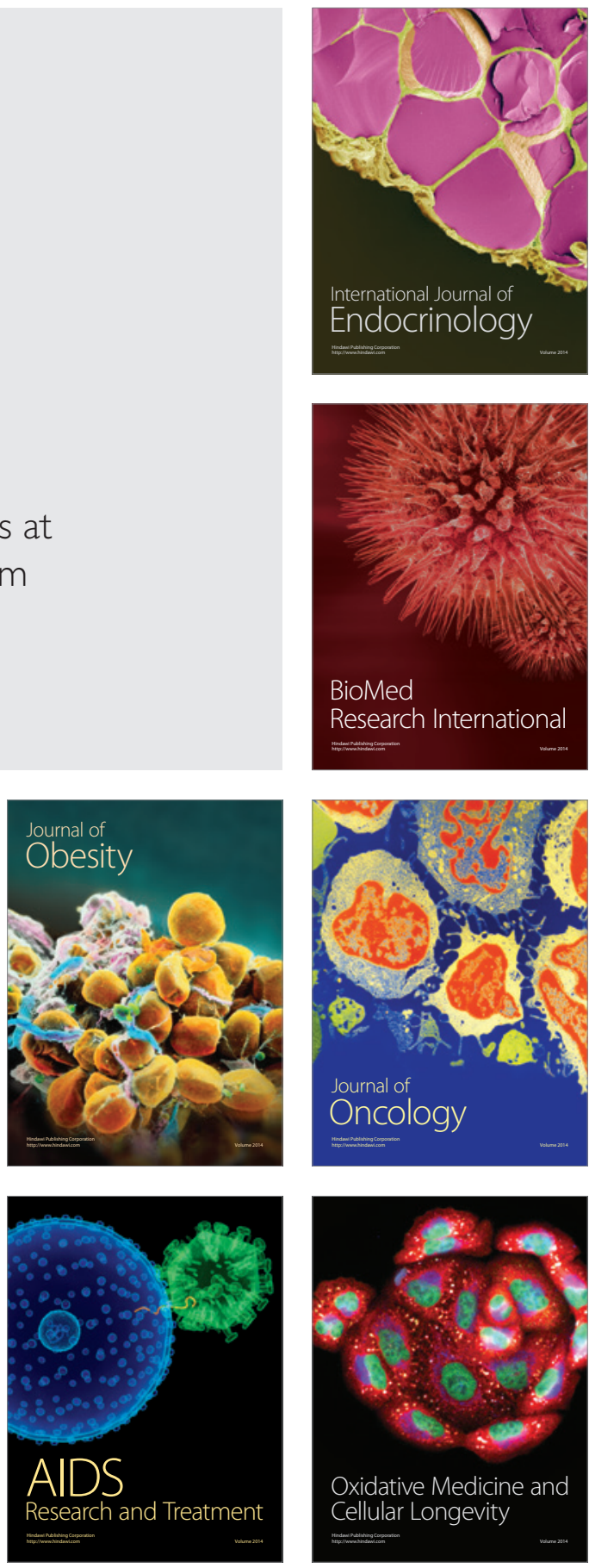